UCRL-53605

Distribution Category UC-21

UCRL --53605

DE85, 007494

\title{
Response of Variable Impedance Stripline to Pulse Excitation
}

\author{
G. McWright
}

Manuscript date: December 15, 1984

\author{
DISCLAIMER
}

Thin repoet wes prepared as in socount of work spowored by an apacy of the United States Government. Neither the United Stetes Governmeat aor any avacy thereof, aoe any of their

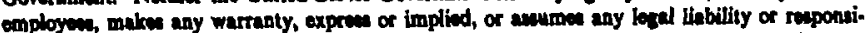
bility for the sccuracy, completerien, or uefolines of any information, apparatus, product, or procese disolond, or represects that its we would not infriage privataly owned sights. Reference herein to any epeciffe commercill produch, proceme, or wervice by trade name, tredemerik, manufecturer, or otherwies does not necentarily comtitule or imply its endorwement, recommeadation, or faworien by the United Stutu Govorament $\alpha$ any esancy thereof. The viow

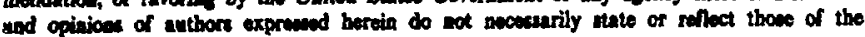
Uaitud Staten Government of any apeccy thereot.

\section{LAWRENCE LIVERMORE NATIONAL LABORATORY University of California - Livermore, California $\cdot 94550$}

Available from: National Technical Information Service - U.S. Department of Commerce 5285 Port Royal Road - Springfield, VA 22161 - \$7.00 per copy - (Microfiche S4.50) 


\section{Contents}

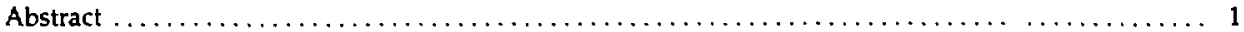

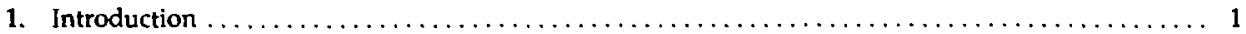

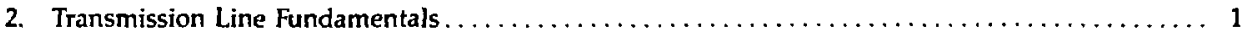

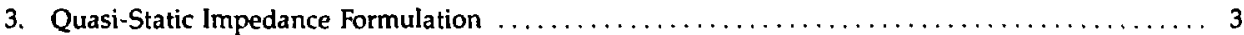

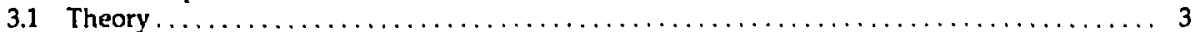

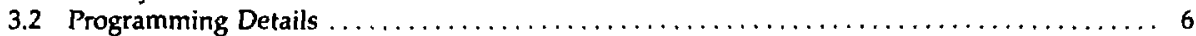

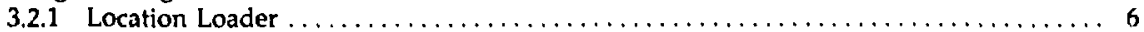

3.2 .2 Relaxation Process $\ldots \ldots \ldots \ldots \ldots \ldots \ldots \ldots \ldots \ldots \ldots \ldots \ldots \ldots \ldots \ldots \ldots, 7$

3.2.3 Capacitance Calculation $\ldots \ldots \ldots \ldots \ldots \ldots \ldots \ldots \ldots \ldots \ldots \ldots \ldots \ldots \ldots \ldots \ldots$

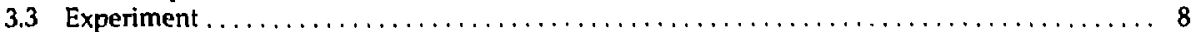

4. Variable Impedance Stripline to Pulse Excitation $\ldots \ldots \ldots \ldots \ldots \ldots \ldots \ldots \ldots \ldots \ldots \ldots \ldots \ldots, 9$

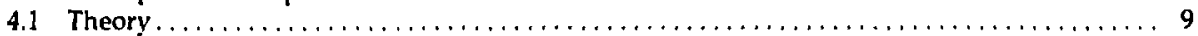

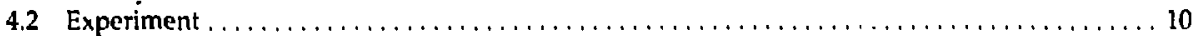

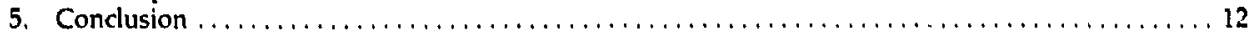

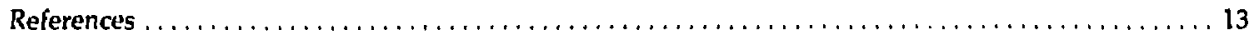

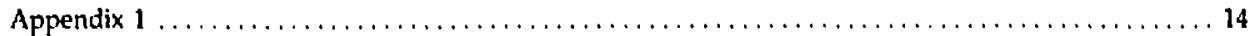

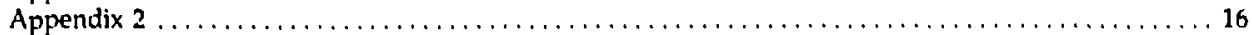

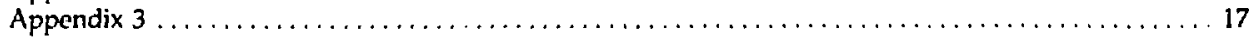




\section{Response of Variable \\ Impedance Stripline to \\ Pulse Excitation}

\section{Abstract}

We describe a simple method to predict the transient response of variable impedance stripline to pulse excitation. The method uses a finite difference based, yuasi-static impedance formulation to calculate the reflection coefficient at each point along the direction of pulse propagation and the subsequent short pulse behavior of a variable imp. stance structure. A Fortran computer program is written to determine the quasi-static impedance. Excellent agreement of better than 1\% between the finite difference impedance predictions and experimental results is noted. A second computer program is written utilizing previous results but essentially incorporating reflection and transmission from several discontinuities to analyze the transient response of the structure. This transient analysis yields good agreement between predictions and results obtained by means. of time domain reflectometry.

\section{Introduction}

The proposed scheme for Nova temporal pulse shaping utilizes passive reflection of a high voltage pulse from nonuniform stripline. The distorted voltage pulse is subsequently applied to a Pockels cell gate to realize a shaped optical pulse. Of considerable interest, then, is the transient response of variable impedance stripline to pulse excitation. In this report, we describe a simple method to predict the resultant voltage shape.

The method uses a finite difference based, quasi-static impeciance formulation; the predicted quasistatic impedance is used to calculate the reflection coefficient at each point along the transmission line and the subsequent short pulse behavior of a variable impedance structure.

We review the transmission line equations in Sec. 2; calculate the quasi-static impedance and compare the finite difference calculations with experimental results in Sec. 3; analyze the transient response of the variable impedance stripline and compare predictions to measurements on the structure made with time domain reflectometry (TDR) in Sec. 4.

\section{Transmission Line Fundamentals}

The voltage, $V$, and the current, $l$, along a lossless, uniform transmission line (Fig. 1) are given by the telegrapher's equations?

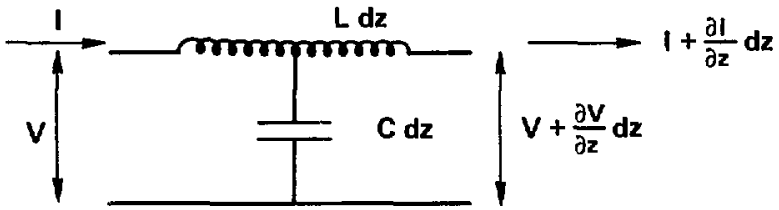

Figure 1. Equivalent circuit of transmission line. 
$\frac{\partial V}{\partial z}=-L \frac{\partial I}{\partial t}$

$\frac{\partial I}{\partial z}=-C \frac{\partial V}{\partial t}$

where $\partial z$ is a differential length of line, and $L$ and $C$ are the inductance and capacitance per unit length, respectively. Differentiating Eq. (1) with respect to distance and Eq. (2) with respect to time, we obtain

$\frac{\partial V^{2}}{\partial z^{2}}=L C \frac{\partial V^{2}}{\partial t^{2}}$

Similarly,

$\frac{\partial t^{2}}{\partial z^{2}}=L C \frac{\partial t^{2}}{\partial t^{2}}$.

The solution of Eq. (3) is

$V=F_{1}(t-z / v)+F_{2}(t+z / v)$

where $F_{1}$ and $F_{2}$ are arbitrary functions of $(t-z / v)$ and $(t+z / v)$, respectively, and the phase velocity, $v$, is

$v=\frac{1}{\sqrt{L C} \text {. }}$

Substituting Eq. (5) into Eq. (1) and integrating with respect to $t$, we obtain

$I=\frac{1}{Z_{i}}\left|F_{1}(t-z / v)-F_{2}(t+z / v)\right|$.

where the characteristic impedance, $Z_{0}$, is

$Z_{i} \quad v \frac{L}{C}$.

Of particular interest is the junction hetween a given uniform line and a line of different characteristic impedance. The total voltage in the line may be regarded as the sum of a voltage in a positive traveling wave equal to $V$, at the point of discontinuity and a voltage $V$, in a reflected wave. Then

$V_{.}+V=V_{1}$,

where $V_{l}$ is the voltage appearing across the the load impedance, $Z_{l}$. Also, the sum of the currents in the positive and negative traveling waves of the line at the discontinuity must equal the current into $Z_{l}$ :

I. $+I=I_{\text {. }}$.

Then

$\frac{V}{Z_{0}}-\frac{V}{Z_{0}}=\frac{V_{1}}{Z_{L}}$

Most importantly, the reflection coefficient, $\rho$, and transmission coefficient, $\tau$, are 


$$
\begin{aligned}
& \rho=\frac{V_{-}}{V_{+}}=\frac{Z_{l}-Z_{0}}{Z_{L}+Z_{0}}, \\
& \tau=\frac{V_{l}}{V_{i}}=\frac{2 Z_{L}}{Z_{J}+Z_{0}} .
\end{aligned}
$$

\section{Quasi-Static Impedance Formulation}

In this section, we use a finite difference approach to calculate the impedance of stripline. The finite difference predictions are subsequently compared with experimental results.

\subsection{Theory}

A cross section of the strip transmission line of interest, here, is shown in Fig. 2. Surrounded by ground planes, the line consists of a strip to which microwave signal is applied. We are interested in determining the impedance

$Z_{0}=\sqrt{\frac{L}{C}}=\frac{\mu \epsilon}{C}$.

We will first calculate the potential throughout the structure using a finite difference equation for the Laplace operator. ${ }^{3,4}$ The function $U(x, y)$ satisfies the linear second-order partial differential equation

$U_{x x}+U_{y i x}=0$,

with the boundary conditions

$$
\begin{aligned}
& U(x, y)=U_{1}=1 \quad \text { (boundary 1) }, \\
& U(x, y)=U_{0}=0 \quad \text { (boundary 2). }
\end{aligned}
$$

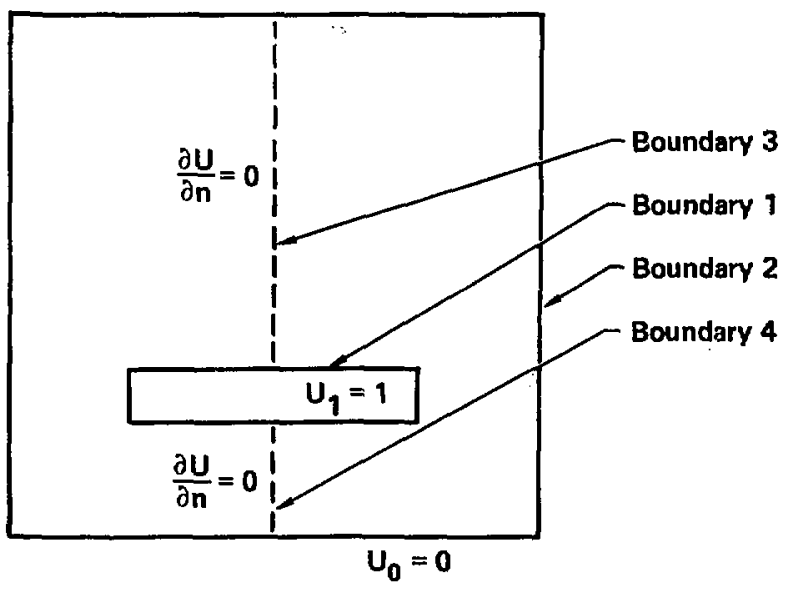


Figure 3(2). Notation for Eq. (19). (a)

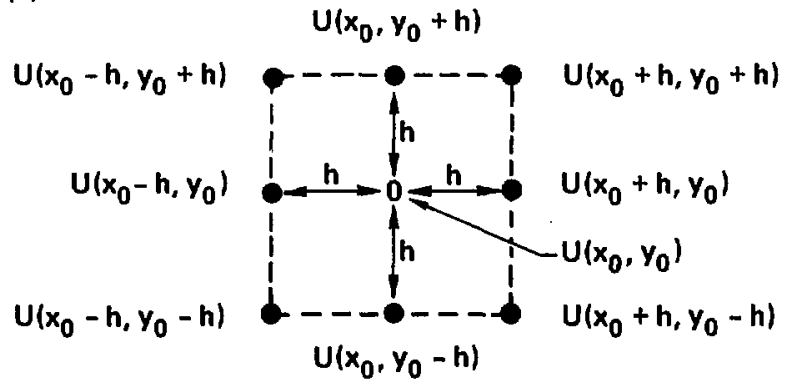

(b)

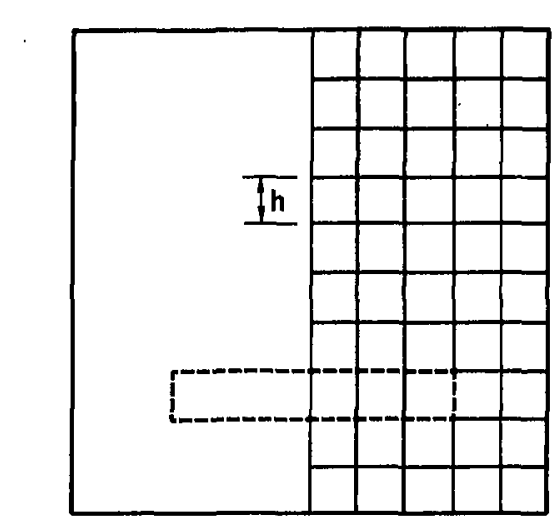

Figure 3(b). Stripline with mesh superimposed.

The problem can be simplified considerably by using the line of symmetry with the additional boundary conditions

$\frac{\partial u}{\partial u}=0 \quad$ (boundaries 3 and 4 ) .

A square mesh with an arbitrary mesh size, $h$, is now superimposed on the sub-domain. By using the notation of Fig. 3 , assuming that $U(x, y)$ has partial derivatives of fourth order near the interior mesh point $\left(x_{1}, y_{1}\right)$, and by using Taylor's theorem, we obtain

$$
\begin{aligned}
& u_{x, x}\left(x_{0,}, y_{0}\right)=\frac{U\left(x_{0}+h, y_{0}\right)+U\left(x_{0}-h, y_{0}\right)-2 U\left(x_{0}, y_{0}\right)}{h^{2}}-\frac{h^{2}}{4 !}\left[u_{x a x}\left(\xi_{1}, y_{0}\right)+U_{x, x}\left(\xi_{2}, y_{0}\right)\right] .
\end{aligned}
$$

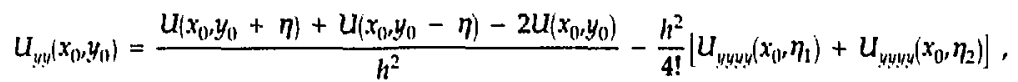

The coordinates $\xi_{1}, \xi_{2}, \eta_{1}$, and $\eta_{2}$ satisfy the following conditions:

$x_{0}-h<\xi_{1}<x_{0}<\xi_{2}<x_{0}+h$, 
$y_{0}-h<\eta_{1}<y_{0}<\eta_{2}<y_{0}+h$.

Combining (15), (19), and (20) we obtain

$U\left(x_{0}+h, y_{0}\right)+U\left(x_{0}-h, y_{0}\right)+U\left(x_{0}, y_{0}+h\right)+U\left(x_{0}, y_{0}-h\right)-4 U\left(x_{0}, y_{0}\right)=\delta\left(h^{4}\right)$

where $\delta\left(h^{4}\right)$ is an error term of fourth order.

Methods for the solution of Eq. (23) along with the associated error analysis have been reviewed extensively. ${ }^{5-7}$ The relaxation technique consists of approximating the function $U(x, y)$ with a funclion $U_{i, k}$ which is only defined for each discrete mesh point. The potential values are continuously modified until all of the simultaneous equations are satisfied to a sufficient degree of accuracy. The simplest numerical procedure is the Liebmann method ${ }^{+}$in which the lattice is scanned along successive columns, and old values for each mesh point are discarded and replaced by new ones. The relaxation formula for the new value of $U_{i, k}^{\prime+1}$ is

$U_{i, k}^{\prime \prime}{ }^{\prime}=\frac{1}{4}\left(U_{i, 1 . k}^{\prime \prime+1}+U_{i+1 . k}^{n}+U_{i, k+1}^{\prime+1}+U_{i, k+1}^{\prime \prime}\right)$

and the potential throughout the structure is thus calculated.

To obtain the capacitance, $C$, and thus the impedance, $Z$, it is necessary to calculate the charge $Q$, on the conductors. ${ }^{N}$ If we form a Gaussian surface with lines parallel to the coordinate directions (Fig. 4), at any foint $P$ on this surface

$D_{n}=\epsilon E_{n}=-\epsilon \frac{\partial u}{\partial n}$.
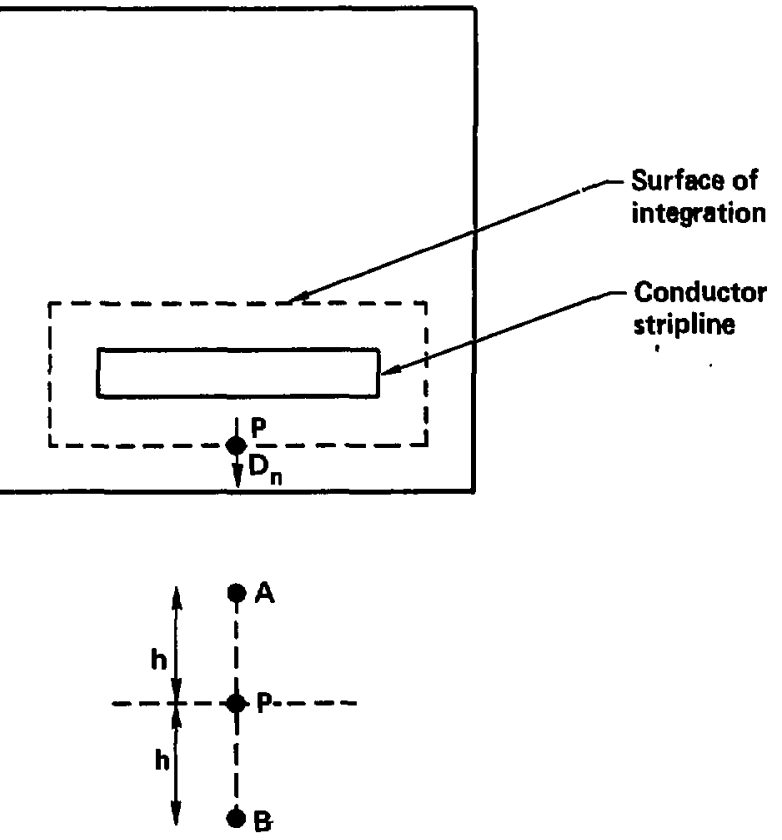

Figure 4. Stripline with Gaussian surface of integration. 
where $n$ is the normal coordinate and $D_{n}$ and $E_{n}$ are the normal components of the displacement and electric intensity, respectively. Expressing $E_{n}$ numerically,

$$
-E_{n}=\frac{\partial U}{\partial n}=\frac{U_{B}-U_{A}}{2 h},
$$

where $U_{B}$ and $U_{A}$ are the potentials on either side of $P$. Thus, if the surface containing the conductor consists of $S$ straight line segments each containing $v$ nodes, the charge per unit length normal to the cross section is

$Q=\epsilon h\left[\frac{\bigvee}{s} \frac{Y_{p}}{p}\left(\frac{\partial U}{\partial n}\right)_{p}\right]$,

where the symbol $\Sigma^{\prime}$ is used to indicate that th. first and last terms in the summation are halved. Then

$C=\frac{Q}{V}$,

where $V$ is the potential difference between the conductors (unity) and the impedance is thus determined.

\subsection{Programming Details}

A Fortran computer program (Appendix 1) implementing the techniques of Sec. 3.1 was developed. The program may be djvided into three sections:

3.2.1 Location Loader

3.2.2 Relaxation Process

3.2.3 Capacitance Calculation

\subsubsection{Location Loader}

The relevant structure is shown in Fig. 5, superimposed on a matrix of size $Y$ by $Z$. The location of the inner conductor, the matrix size, and the number of relaxation cycles are input by the operator in the following order:

UL1, UL2, UR1, UR2, LL1, LL2, LR1, LR2, Y, Z, N

where

UL1, UL2 are row, column of upper left coordinate of inner conductor,

UR1, UR2 are row, column of upper right coordinate of inner conductor,

LL1, LL2 are row, column of lower left coordinate of inner conductor,

LR1, LR2 are row, column of lower right coordinate of inner conductor,

$Y, Z$ are row, column of complete structure,

$\mathrm{N}$ is the number of relaxation cycles. 


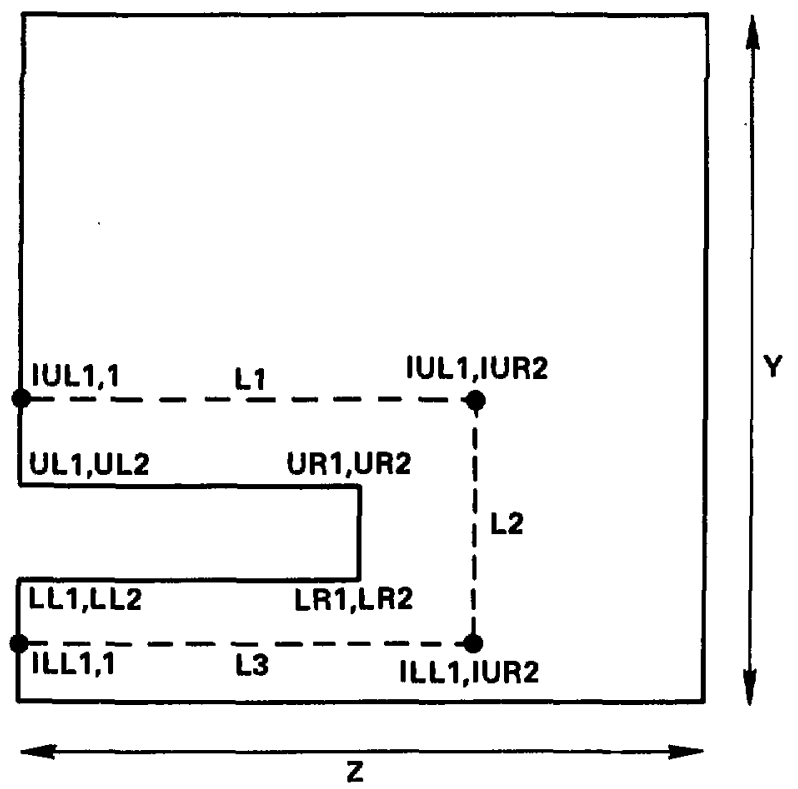

Figure 5. Line segments for capacitance calculation.

A constant potential $U_{1}=1$ is assigned to all mesh points on the inner boundary and $U_{0}=0$ to all points on the outer boundary. An initial value is assigned to all interior mesh points:

$$
\begin{array}{cr}
\mathrm{U}_{\mathrm{J} . \mathrm{K}}^{0}=(\mathrm{Y}-\mathrm{J}) /(\mathrm{Y}-\mathrm{LL} 1) & \mathrm{LL} 1+1 \leq \mathrm{J} \leq \mathrm{Y}-1 \\
& 1 \leq \mathrm{K} \leq \mathrm{LR} 2, \\
\mathrm{U}_{\mathrm{J}, \mathrm{K}}^{0}=(\mathrm{J}-\mathrm{1}) /(\mathrm{UL} 1-1) & 2 \leq \mathrm{J} \leq \mathrm{UL} 1-1 \\
& 1 \leq \mathrm{K} \leq \mathrm{UR2}, \\
\mathrm{U}_{\mathrm{J} . \mathrm{K}}^{0}=\mathrm{U}(\mathrm{J}, \mathrm{LR} 2)[(\mathrm{Z}-\mathrm{K}) /(\mathrm{Z}-\mathrm{LR} 2)] & 2 \leq \mathrm{J} \leq \mathrm{Y}-1 \\
\mathrm{UR2}+1 \leq \mathrm{K} \leq \mathrm{Z}-1 .
\end{array}
$$

\subsubsection{Relaxation Process}

The relaxation procedure consists of scanning successive columns from left to right and continuously modifying the potential according to Eq. (24):

$U_{i, k}^{\prime \prime+1}=\frac{1}{4}\left(U_{i-1, k}^{n+1}+U_{i+1, k}^{n}+U_{i, k-1}^{\prime \prime+1}+U_{j, k+1}^{\prime \prime}\right)$.

Equation (24) is modified along the mirror surface (Column 1):

$U_{j, 1}^{n+1}=\frac{1}{4}[2 U(j, 2)+U(j-1,1)+U(j+1,1)]$. 


\subsubsection{Capacitance Calculation}

The capacitance calculation consists of determining an integration contour around the inner conductor, calculating the total charge according to Eq. (27), and dividing by the potential difference. Line segments L2 and L3 lie halfway between the inner conductor and the ground plane. Line segments L1 and L3 are the same distance from the inner conductor. That is, let

$I U L 1=U L 1-[(L L 1+Y) / 2-L L 1]$.

ILL1 $=(L L 1+Y) / 2$,

L.UR2 - (LR2 - Z)/2 .

Thus the points (IUL1,1), (IUL1, IUR2), (ILL1, IUR2) and (ILL1,1) determine the three relevant line segments (Fig. 5) and the total charge may be calculated according to the methods of Sec, 3.1.

\subsection{Experiment}

Impedance predictions from the finite difference analysis are compared with experimental results from a fabricated stripline. The impedance of the stripline is determined by means of time domain reflectometry (TDR)." TDR analysis is based on the reflection of voltage from a discontinuity or perturbation in a transmission system. The cortponents of the HP 7S12 TDR system include a fast-rising voltage step generator $\left(t_{r}<25 \mathrm{ps}\right)$, a sampling oscilloscope $\left(t_{r}<30 \mathrm{ps}\right)$, and a transmission line system. The reflection coefficient us signal propagation time is read directly from the oscilloscope, and the impedance of the stripline may be calculated from Eq. (12).

A comparison between the finite difference predictions obtained using the computer program in Appendix 1 and experimental results is shown in Fig. 6 for a stripline structure. Agreement of better than $1 \%$ between theory and experiment is noted for all four cases. Exact mesh size details are given in Appendix 2.

Figure 6. Finite element impedance predictions and experimental results.

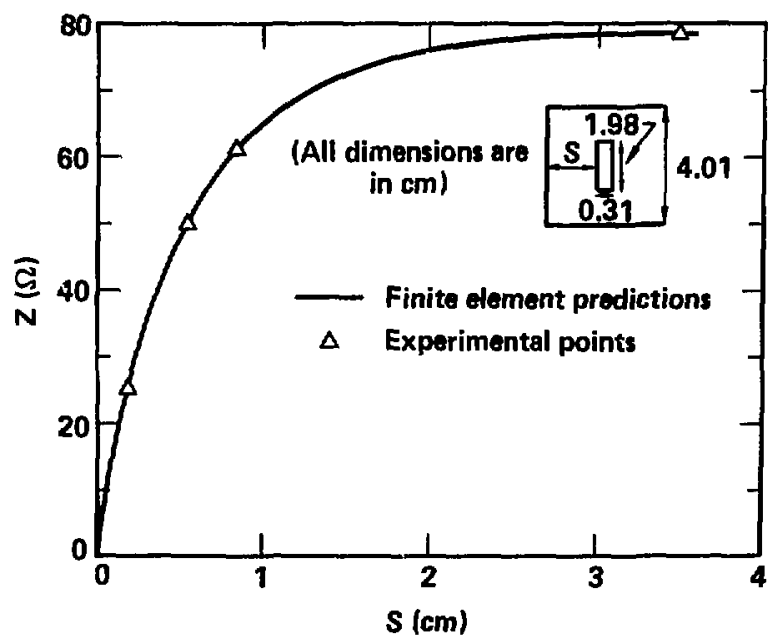




\section{Variable Impedance Stripline to Pulse Excitation}

We are interested in determining the reflected voltage from a variable impiedance stripline system (Fig. 7). Note that the impedance variations for the structure of interest are the result of differences in conductor to ground plane spacing in the direction of pulse propagation. We assume the following:

1. A pure TEM mode is excited at $Z=0$ (and extracted after reflection).

2. Coupling to higher order modes along the direction of propagation is negligible.

3. The stripline system is non-dispersive.

\subsection{Theory}

A schematic representation of the variable impedance stripline is shown in Fig. \&. We have approximated the continuous impedance variation by a series of steps in the tronsmission line. Reflertion and transmission from a single discontinuity have been examined in Sec. 2. Here; we analyze reflectiori and transmission from several discontinuities.

Consider two time-separated discontinuities (Fig. 9); the actual reflection caused by $\rho_{2}$ will be altered by $\rho_{1}$ before the actual $\rho_{2}$ arrives at the TDR. ${ }^{4}$ Manipulating Eqs. (9), (12), and (13) we obtain

$$
V_{+}(1+\rho)=\tau \text {. }
$$

The incident and reflected voltages from the second discontinuity are $V_{+}\left(1+\rho_{1}\right)$ and $V_{+}\left(1+\rho_{1}\right) \rho_{2}$ respectively. The voltage appearing at the oscilloscope is $V_{+}\left(1+\rho_{1}\right)\left(1-\rho_{1}\right)$. Note that the reflection coefficient changes sign for travel in the opposite direction. Then,

$\frac{\rho_{2}}{\rho_{2}}=\frac{\text { measured value }}{\text { true value }}=\left(1+\rho_{1}\right)\left(1-\rho_{1}\right)=1-\rho_{\mathrm{i}}^{2}$.

For a system of three discontinuities

$\frac{\rho_{3}^{\prime}}{\rho_{3}}=\frac{\text { measured value }}{\text { true value }}=\left(1-\rho_{1}^{2}\right)\left(1-\rho_{2}^{2}\right)$.

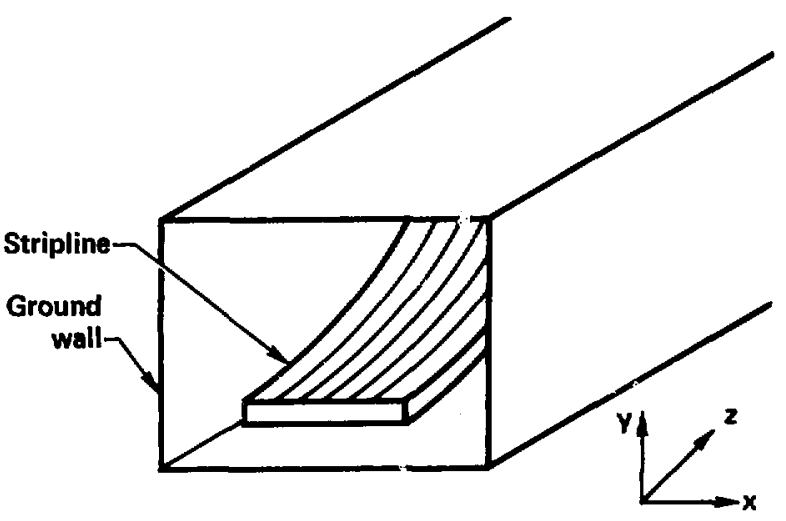

Figure 7. Variable inspedance stripline. 
Figure 8. Schematic representation of variable impedance stripline.

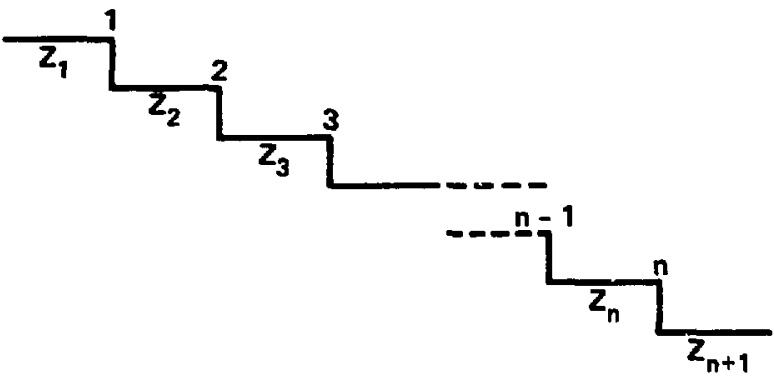

By induction, the error in the nth discontinuity with $\|-1$ discontinuities between it and the sampling scope is

$\frac{p_{1 i}}{\rho_{1}}=11-\rho_{i}^{i}\left(1-\rho_{i}^{2}\right) \cdots\left(1-\rho_{i}^{i}\right)$.

The relevant computer program is described in Appendix 3 . The reflection snefficient at each point along the direction of pulse propagation is calculated from the quasi-static impedance. The velocity of propagation is

$\because=\frac{1}{i L C}=i$

From Eqs. (40) and ( 41 ), the reflection coefficient vs pulse propagation time is calculated, and the short pulse behavior of a variable impedance stripline is thus determined.

\subsection{Experiment}

Experimental results from a variable impedance stripline structure are subsequently compared with predictions. Again, the short-pulse behavior is determined by time domain reflectometry. A structure similar to that of Fig. $7 \mathrm{i}$ : labricated. Actual dimensions along with finite element impedance predictions are given in Fig. 10. The rivicture is approximately $30 \mathrm{~cm}$ long ( 2 direction), and the impedance variations along the $\mathrm{z}$ direction can . Thitrarily adjusted by varying the conductor-to-ground-plane spacing with a series of micrometers.

Figure 9. Reflection and transmission from two time separated discontinuities.

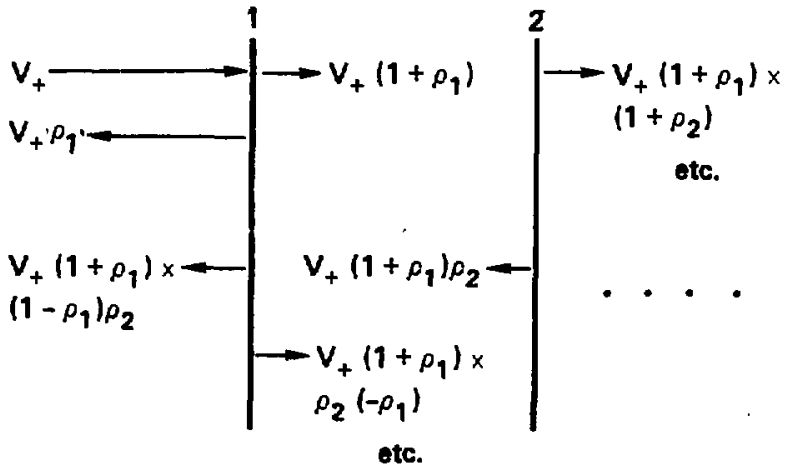




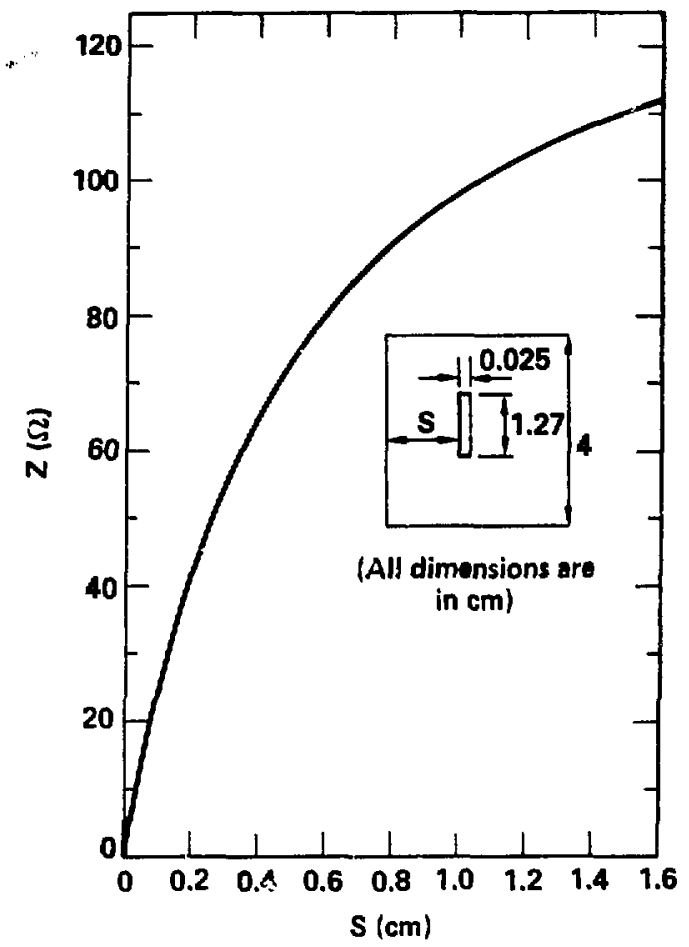

Figure 10. Finite element impedance predictions used for transient analysis.

The computer predictions and experimental results of Figs. 11 to 13 are obtained as follows:

1. Measure the conductor-to-ground-plane spacing, which varied along the $z$ direction.

2. Calculate the corresponding impedance using the finite difference formulation of Sec. 3 .

3. Determine the reflection coefficient vs signal propagation time using the analysis of Sec. 4 .

4. Compare to results obtained from an HP 7912 TDR.

Good agreement between theory and experiment is noted for all three cases, although the computer predictions tend to overestimate the reflection coefficient at later times. We attribute this discrepancy to rapid changes in the conductor-to-ground plane spacing along the $z$ direction that cause unwanted coupling to higher order modes and subsequent invalidation of the assumptions of Sec. 4.

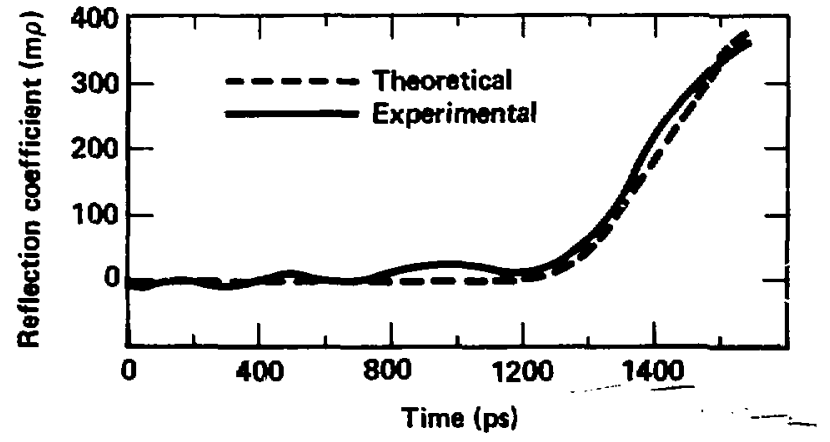

Figure 11. Transient predictions and experimental results. 


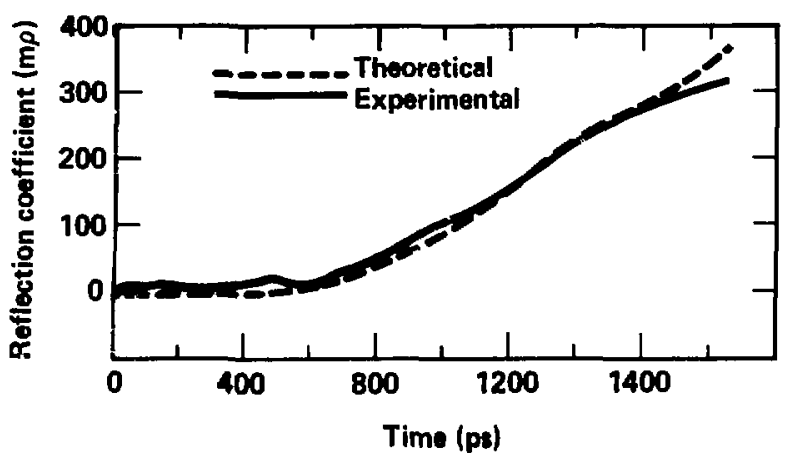

Figure 12. Transient predictions and experimental results.

Figure 13. Transient predictions and experimental results.

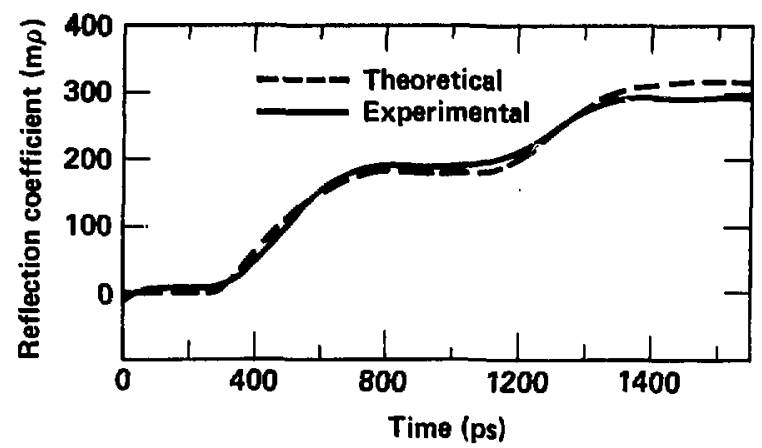

\section{Conclusion}

We describe a simple method to predict the transient response of variable impedance stripline to pulse excitation. This technique uses a finite difference based quasi-static impedance formulation to calculate the reflection coefficient at each point along the direction of pulse propagation; the short pulse behavior of the structure is thus determined. Excellent correlation between the finite difference impedance predictions and experimental results is noted. Incorporation of the finite difference impedance calculations into the transient analysis yields good agreement between predictions and results obtained by time domain reflectometry (TDR). 


\section{References}

1. 1983 Laser Program Annual Report, Lawrence Livermore National Laboratory, Livermore, CA, UCRL50021-83 (1984), pp. 2-20 to 2-21.

2. S. Ramo, J. Whinnery, and T. Van Duzer, Fields and Waves in Communication Electronics (John Wiley and Sons, New York, 1965), pp. 23-61.

3. R. A. Waldon, Theory of Guided Electromagnetic Waves (Van Nostrand Reinhold, London, 1969), Pp. 157-170.

4. M. V. Schneider, "Computation of Impedance and Attenuation of TEM-Lines by Finite Difference Methods," IEEE Trans. Microwave Theory and Techniques 13, 793-800 (1965).

5. K. J. Binns and P. J. Lawrenson, Analysis and Computation of Electric and Magnetic Field Problems (Pergamon Press, Oxford, 1973), pp. 241-285.

6. L. F. Richardson, "The Approximate Arithmetical Solution by Finite Differences of Physical Problems Involving Differential Equations, with an Application to the Stresses in a Masonry Dam," Phil. Trans, 210A, 307 (1911).

7. P. Silvester and M. S. Hseih, "Finite Element Solution of 2-Dimensional Exterior Field Problems," Proc, IEE 118, 1743 (1971).

8. Harry E. Green, "The Numerical Solution of Some Important Transmission-Line Problems," IEEE Trans. Microwave Theory and Techniques 13, 676-692 (1965).

9. P. E. Allen, Annlysis of Transmission Systems by Time Domenin Reflectometry, Lawrence Livermore National Laboratory, Livermore, CA, UCRL-12319 (1965). 


\section{Appendix 1}

C FINITE DIFFEFENCE PROGRAM (MICFOSDFT FORTRAN) TO CALCULATE

C IMPEDANCE OF STRIPLINE SUFROUNDED ON ALL SIDES BY GROUND

C FLANES. WRITTEN EY GLEN MCWRIGHT, AUGUST 1984. INTEGEF UL1 (10), UL2 (10), UF1 (10), URE (10), LL1 (10), LL2(10)

INTEGER LR1 (10), LRZ (10),Y(10),Z(10),J,K,N(10), A,M

INTEGEF IUL 1, ILL 1 , IUR2, B, Q, NQ, YQ, UF:1Q, ZQ, UR2Q, LL1Q

FEAL U $(500,101), A V G 1,51,52,53$, IMF
C INFUT NLMEER QF CASES (MAX DF 799 )

READ $(*, 3) \mathrm{B}$

3 FORMAT (IIS)

DD $8 M=1, B$

C INFUT COORDINATES OF CENTER CONDUCTOR, GFOUND PLANES, AND

C NUMBER DF ITEFATIONS

READ (*,5) UL1 (M), UL2 (M), UF1 (M), URZ (M), LL1 (M), LL2 (M),

*LFII $(M), L F Z(M), Y(M), Z(M), N(M)$

5 FORMAT (10Iక, I 4 )

B CONTINUE

C. SET FDTENTIAL TO ZERO THFOUGHOUT STRUCTUFE

DC $400 \quad Q=1, E$

$D O 20 \quad J=1, \dot{Y}(Q)$

DD $10 \quad K=1, Z(0)$

$U(\mathfrak{J}, K)=0$.

10 CONT INUE

20 CONTINUE

i.

SET FOTENTIAL TO UNITY ON CENTER CONDUCTOR

DO $40 \quad J=$ UL. 1 (Q), LL 1 (Q)

DO $30 k=$ UL.2 (Q), UFZ (Q)

$U(J, K)=1$.

30 CONT INUE

40 CONT INUE

c

CALCLLATE INITIAL GUESSES FDF FUTENTIAL THFDUGHOUT STFUETURE

DD $60 \mathrm{~J}=\mathrm{LL} 1(\mathrm{Q})+1, Y(Q)-1$

DD $50 \quad K=1, L F 2(Q)$

$U(J, K)=1 . *(Y(Q)-J) /(Y(Q)-L L 1(Q))$

50 CDNTINUE

60 CONT INUE

DD $80 \mathrm{~J}=2$, ULL $1(Q)-1$

DD $70 k=1, U F 2(Q)$

$U(J, K)=1 . *(J-1) /(U L 1(\mathrm{D})-1)$

70 CONT INUE

90 CONT INUE

DO $100 \mathrm{~J}=2, \gamma(Q)-1$

DO $90 K=\operatorname{LR} 2(Q)+1, Z(Q)-1$

AVG $1=1 . *(Z(Q)-K) /(Z(Q)-L F Z(Q))$

90 CONT INUE

100 CDNT INUE

$N G=N(Q)$

$Y Q=Y(Q)$

UR: $1 Q=U R 1(Q)$

URZQ $=$ UR2 (Q)

$Z Q=Z(Q)$

LL $1 Q=L L 1(Q)$ 
DO $140 \quad A=1, N G$

DO $110 \mathrm{~J}=2$, UFi $1 \mathrm{Q}-1$

$U(J, 1)=0.25 *(2 . * U(J, 2)+U(J-1,1)+U(J+1,1))$

110 CONTINUE

DO $115 \mathrm{~J}=\mathrm{LL} 1 \mathrm{Q}+1, Y \mathrm{Y}-1$

$U(J, 1)=0.25 *(2 . * U(J, 2)+U(J-1,1)+U(J+1,1))$

115 CONTINUE

DO $1.20 \quad K=2, U R 2 G$

DQ $117 \mathrm{~J}=2$, UFi $1 \mathrm{Q}-1$

$U(J, K)=0.25 *(U(J-1, K)+U(J+1, K)+U(J, K-1)+U(J, K+1))$

117 CONTINUE

DO $119 \mathrm{~J}=\mathrm{LL} 1 \mathrm{Q}+1, Y Q-1$

$U(J, K)=0.25 *(U(J-1, K)+U(J+1, K)+U(J, K-1)+U(J, K+1))$

119 CONT INUE

120 CONT INUE

DO 135 K $=$ UF2Q+1, $20-1$

DO 130,$]=2, Y Q m-1$

$U(\mathrm{~J}, K)=0.25 *(U(\mathrm{~J}-1, K)+U(J+1, K)+U(J, K-1)+U(J, K+1))$

130 CONTINUE

135 CONTINUE

140 CONTINUE

WFITTE (*, 15O) UL1 (Q), ULZ (Q), UF1(Q), UR2(Q), LL1(Q), LL2(Q), *LFI (Q), LFI (Q), $Y(O), Z(0), N(Q)$

C. DETEFMINE GAUSSIAN SUFFACE OF INTEGFATIDN

150 FOFIMAT $(1 X, 11$ IS $)$

IUL $1=\operatorname{UL} 1(0)-((1 . L .1(Q)+Y(Q)) / 2-L L 1(Q))$

ILL $1=(L L 1(0)+Y(B)) / 2$

IUF: $2=\{L F 2(Q)+Z(Q)), 2$

C CALLULATE CHAFGE ALONG EACH SEgMENT of gaUSSian SURFACE

$51:=0$.

DO $250 \quad K=2$, IUR $2-1$

$51=51+0.5 *(U(\operatorname{ILL} 1-1, K)-U(\operatorname{ILL} 1+1,1)$

250 CLNTINUE

$\left.51=0.25 *(L)\left(I L L 1-1, I U F_{2}\right)-U(Y L L 1+1, I L F 2)\right)+S 1$

$\mathrm{g} 2=0$.

DD $270 \quad I=14 ! 1-1, I L 11-1$

$S 2=52+0.5 *(U)(J, I U F 2-1)-U(J, I U F 2+1)$

270 CONT INUE

$S 2=0.25 *(U)($ ILL 1, IURZ-1) $-U($ ILLL1, IUF $2+1))+$

*0. 25*(U(IUL 1, I UF $2-1$ )-U(IUL 1, IUR2+1) ) +. 32

$53=0$.

DO $290 \quad K=2, I U F 2-1$

$5 \Xi=5 \Xi+0.5 *(U($ IUL $1+1, K)-U($ IUL $1-1, K))$

290 CONT INUE

$5 S=0.25 *$ (U (IUL $1+1$, IUF 2$)-U($ I UL 1 -1, IURZ) ) +SS

C

CALCLLATE TOTAL CHARGE

$\mathrm{CH}=2 . *(S 1+52+S 3)+0.5 *(U(\operatorname{IUL} 1+1,1)-U(\operatorname{IUL} 1-1,1)\}+$

*0. $5 *(U(I L L .1-1,1)-U(\operatorname{ILL} 1+1,1))$

IMF:=377. $/ \mathrm{CH}$

WFITE $(*, 300)$ IMF

SOO FOFMAT ( $1 \times$, FG. 5 )

400 CONT INLIE

STOF

END 


\section{Appendix 2}

Computer input for finite element calculations of Fig. 6. mesh size, $h=0.1 \mathrm{~cm}$.

$$
\begin{array}{ll}
S=0.3 \mathrm{~cm} & 095001095011098001098011101021999 \\
S=0.4 & 094001094011097001097011101021999 \\
S=0.5 & 093001093011096001096011101021999 \\
S=0.6 & 092001092011095001095011101021999 \\
S=0.7 & 091001091011094001094011101021999 \\
S=0.8 & 090001090011093001093011101021999 \\
S=0.9 & 089001089011092001092011101021999 \\
S=1.0 & 088001088011091001091011101021999 \\
S=1.4 & 084001084011087001087011101021999 \\
S=1.8 & 080001080011083001083011101021999 \\
S=2.4 & 074001074011077001077011101021999 \\
S=3.0 & 068001068011071001071011101021999 \\
S=3.6 & 162001162011165001165011201021999
\end{array}
$$




\section{Appendix 3}

C FROGRAM (MICROSOFT FORTRAN) TO CALCULATE TRANSIENT

C FESFONSE DF STRIFLINE TO FULSE EXCITATIDN. WRITTEN

C EY GLEN MCWRIGHT, NOVEMBER 1984.

INTEGER $A, B, C, D, E, F, G$

REAL $Z(50), P(50), P R(50), T D R(50), F F(50)$

C INPUT NUMEER OF IMFEDANCE STEFS

FEAD $(*, 5) A$

5 FQFMAT (IS)

DO $10 \quad B=1, A$

C INFITT IMFEDANCE:

FEEAD (*,8) $Z$ (B)

a FOFMAT (F7.2)

10 CONT INUE

DO $20 \quad C=1, A-1$

C CALCULATE REFLECTION COEFFICIENT"

$F(C)=(Z(C+1)-Z(C)) /(Z(C)+Z(C+1))$

20 CONTINUE

C CALCULATE REDUCED REFLECTION COEFFICIENT'

$F F(2)=(1 .-\{F(1) * F(1)))$

DO $30 \quad D=3, A-1$

$F F(D)=(1 .-(F(D-1) * F(D-1))) * P F(D-1)$

30 CONTINUE

$P F(1)=P(1)$

DO $40 \quad G=2, A-1$

$F P(G)=P F(G) * P(G)$

40 CONTINUE

TDR $(1)=F F(1)$

Do $50 E=2, A-1$

TDF $(E)=T D R(E-1) \quad+F P(E)$

SO CONT INUE

C FFINT REDUCED REFLECTION COEFFICIENT AT EACH IMPEDANCE STEF DO $50 \quad F=1, A-1$

WFITE (*,5S) TDR (F)

55 FOFIMAT $(1 X, F B .5)$

SO CONTINUE

STOF

END 